\title{
Cystic Fibrosis Late Diagnosis: A Case Report
}

\section{de Moraes Júnior RM, Mota GS, Carolino MLO, Marques Junior OS and Kerche-Silva LE*}

Medical School of Presidente Prudente, Western São Paulo University, Brazil

\begin{abstract}
Cystic Fibrosis (CF) is an autosomal recessive disease that affects mucus and sweat producing cells involving multiple organs. CF is usually diagnosed in childhood; however, a considered number of adults are diagnosed every year. Atypical CF can be a milder form of the CF disorder, and individuals with atypical CF can remain undiagnosed for many years. Physicians should suspect of CF in adult individuals when these present recurrent pneumonia or bronchiectasis. Therefore, since early diagnosis of CF can avoid morbidities and unnecessary hospitalizations, the recognition of CF symptoms by clinicians is necessary to avoid late diagnosis.
\end{abstract}

Keywords: Late diagnosis; Atypical cystic fibrosis; Cystic Fibrosis (CF)

\section{Introduction}

Cystic Fibrosis (CF) is a recessive disease involving an autosomal gene, the Cystic Fibrosis Trans-membrane Conductance Regulator (CFTR) gene located at 7q31.2, which regulates the activity of chloride and sodium channels at the surface of the epithelium cell [1-3]. This disease affects the cells that produce mucus and sweat in multiple organs, being the lung the most severely affected and responsible for $90 \%$ of the deaths in patients with CF [4].

Defective CFTR protein results in thick and sticky mucus that can obstruct the pathways, since CFTR proteins in normal conditions lets chloride ions to pass through the mucus producing cells carrying water and making the mucus thinner [5]. These obstructions, especially in the lungs, lead to massive neutrophil infiltration that induces the release of elastase that stimulates the lung antiproteases increasing lung destruction [6]. Besides the tissue destruction, neutrophils degranulation contributes to the mucus hyperviscosity since it releases a large amount of nucleic acids and cytosol matrix proteins [7]. Following the lungs, the GIT are severely affected since the mucous plugs obstruct pancreas enzymes and bile flow into the duodenum resulting in digestion abnormalities and malabsorption. Some patients present Distal Intestinal Obstruction Syndrome (DIOS) characterized by ileocecal obstruction of inspissated intestinal contents due to pancreatic insufficiency [8,9]. Although all these symptoms associated to GIT is involved as a multiorgan manifestation, they have not yet been systematically quantified. Tabori et al. [10] showed that patients with a severe course of the disease or with genotypes causing a moderate to severe abdominal involvement have more GI symptoms and that these symptoms are not associated with liver disease (CFLD) or elevated Liver Function Tests (LFTs).

Bronchiectasis, chronic infections associated with pneumonia, hemoptysis, pneumothorax and respiratory failures are complications associated with CFTR defected protein in respiratory system. GIT complications include nutritional deficiencies, including vitamins deficiencies and diabetes, progressive hepatic dysfunction, gallstones, intestinal obstruction, Small Intestine Bacterial Overgrowth (SIBO) and DIOS. Normally, infertility, osteoporosis, electrolyte imbalances, dehydration, fatigue, weakness and really low blood pressure are other complications associated with CF [11].

The aim of this work is to report a 28 years old female that was diagnosed with $\mathrm{CF}$.

\section{Case Report}

28 years old female was referred to Emergency Room of the
Regional Hospital of Presidente Prudente (HRPP) with worsening dyspnea accompanied by greenish vomit, inappetence, epigastric pain, and paresthesia of the right upper limb. She did not have a history of smoking or alcoholism. She complained of weight loss, holocranial headache and cough with expectoration. There was absence of relevant complaints in the other systems.

The patient history showed that she was born vaginally, weighting $2,780 \mathrm{~g}$, and $51 \mathrm{~cm}$ of height. At 15 days of life she presented her first lung manifestation with pleural effusion. At 5 years old she started with a history of upper and lower airway infections episodes that were refractory to the proposed treatments. By 13 years old she underwent her first surgical procedure, a right inferior and middle lobectomy. Three years after her first surgery, she was submitted to a new pulmonary lobe resection, a superior right lobectomy. Four years later, she underwent amputation of the right bronchial stump which presented chronic inflammatory processes with fibrosis, hyalinization and hemorrhagic areas. Figure 1 shows the images of flexible bronchoscopy that was made before and after the amputation of the right bronchial stump.

On examination she presented good general condition, afebrile, acyanotic, aniceric, stained, hydrated and with tachypnea. Her heart rate was 88 beats per minute; her respiratory rate was 28 breaths per minute. Auscultation revealed rhythmic heart rate and vesicular murmur in the left hemithorax with presence of crepitant rales on the left pulmonary base. Her abdomen was flat, normotensive, with hidroaereos noises and without visceromegalias.

Based on the history of the patient, the initial diagnosis was of residual bronchiectasis of the left lung, with the suspicious of cystic fibrosis. She was admitted in the HRPP for the $5^{\text {th }}$ time in the period of 1 year for complaints regarding pulmonary affections, and this time she was diagnosed with opportunistic infection by Mycobacterium abcessus. The patient also underwent pilocarpine sweat iontophoresis and the diagnosis of Cystic Fibrosis was confirmed. The patient was then treated with $600 \mathrm{mg}$ Amikacin, $500 \mathrm{mg}$ Clarithromycin, $2 \mathrm{~g}$ Cefepime and $400 \mathrm{mg}$ Ciprofloxacin.

*Corresponding author: Kerche-Silva LE, Medical School of Presidente Prudente, Western São Paulo University, Brazil, Tel: +551832291000; E-mail: leakerche@unoeste.br

Received May 04, 2017; Accepted May 15, 2017; Published May 25, 2017

Citation: de Moraes Júnior RM, Mota GS, Carolino MLO, Marques Junior OS, Kerche-Silva LE (2017) Cystic Fibrosis Late Diagnosis: A Case Report. Lung Dis Treat 3: 123. doi:10.4172/2472-1018.1000123

Copyright: (c) 2017 de Moraes Júnior RM, et al. This is an open-access article distributed under the terms of the Creative Commons Attribution License, which permits unrestricted use, distribution, and reproduction in any medium, provided the original author and source are credited. 
Citation: de Moraes Júnior RM, Mota GS, Carolino MLO, Marques Junior OS, Kerche-Silva LE (2017) Cystic Fibrosis Late Diagnosis: A Case Report. Lung Dis Treat 3: 123. doi:10.4172/2472-1018.1000123

Page 2 of 3

After diagnostic confirmation, the patient was hospitalized five more times in a period of four years as a consequence of infected bronchiectasis. She underwent respiratory physiotherapy and she was treated with $500 \mathrm{mcg} /$ day Beclomethasone and $100 \mathrm{mcg}$ Salbutamol when necessary. In March of this year (2017) she underwent a spirometry that showed a very severe obstructive disorder, that slowed her vital forced capacity to $34 \%$ of the expected value. Nowadays she has been using $24 \mathrm{mcg} /$ day Formoterol and presents dyspnea to small efforts. Figure 2 shows images of a recent CT showing the absence of the right lung and the presence of bronchiectasis.

\section{Discussion and Conclusion}

Cystic Fibrosis (CF) is a genetic condition with high prevalence among Caucasian populations with an incidence of 1:2500 live births. One in 25 persons is asymptomatic carriers. CF can be diagnosed at birth for early medical and nutrition intervention that can lead to improved outcomes $[12,13]$. And although most people with classic CF will be diagnosed through newborn screening or symptoms in early childhood, there are atypical forms of CF that will only be recognized in adults. The diagnosis in the first year of life is typically accompanied of meconium ileus, failure to thrive, pulmonary infections, diarrhea, and steatorrhea. In adults, patients usually present respiratory symptoms or male infertility due to Congenital Bilateral Absence of the Vas Deferens (CBAVD) [14].

The data from CF Foundation showed in 2001 that in an $n=100$, $9.9 \%$ of the new diagnoses in US occur in the age of 18 or older. The tendency is that this rate must increase, since the identification of over 1000 mutations now makes possible the diagnosis in those who have atypical symptoms or equivocal sweat test results [15].

Wilde research has been showing that the individuals who are diagnosed in a late age display better lung function, higher rates of pancreatic sufficiency, fewer complications, and longer life expectancy than those who are diagnosed at birth or as children. They also can live a normal life, being married and working full time [16-18]. However, a study has shown that late diagnosis does not mean good prognosis. In
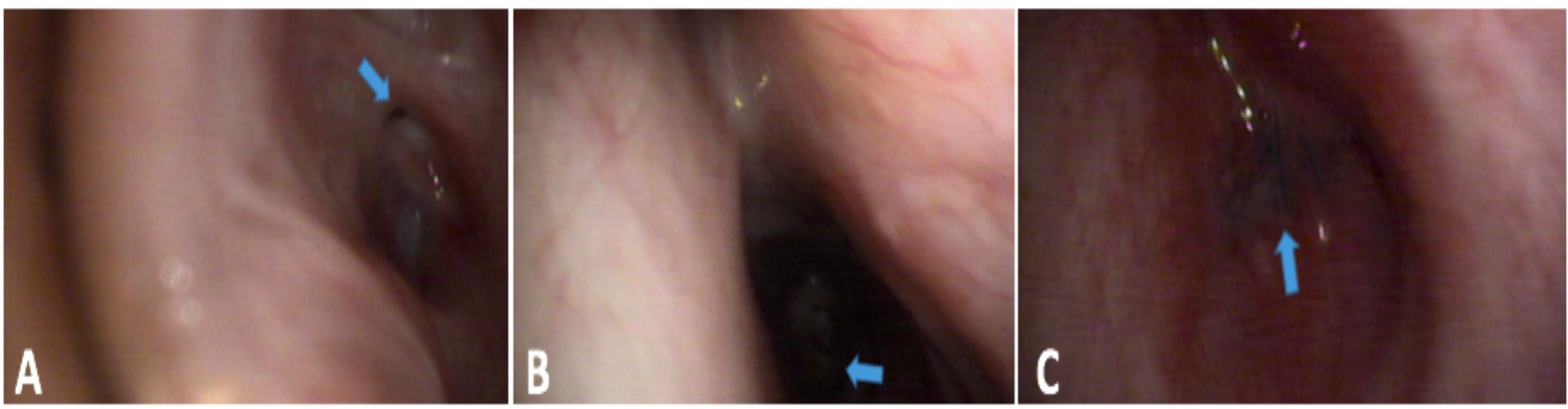

Figure 1: Flexible bronchoscopy before the amputation of the right bronchial stump showing: A) Right bronchial stump of $4 \mathrm{~cm}$ with fistulous orifice (evidenced by the narrow); B) Left main bronchus with preserved mucosal relief and great amount of thick mucous (evidenced by the narrow); and C) Flexible bronchoscopy after the amputation of the right bronchial stump showing the stump hyperemia and suture exposure (evidenced by the narrow).

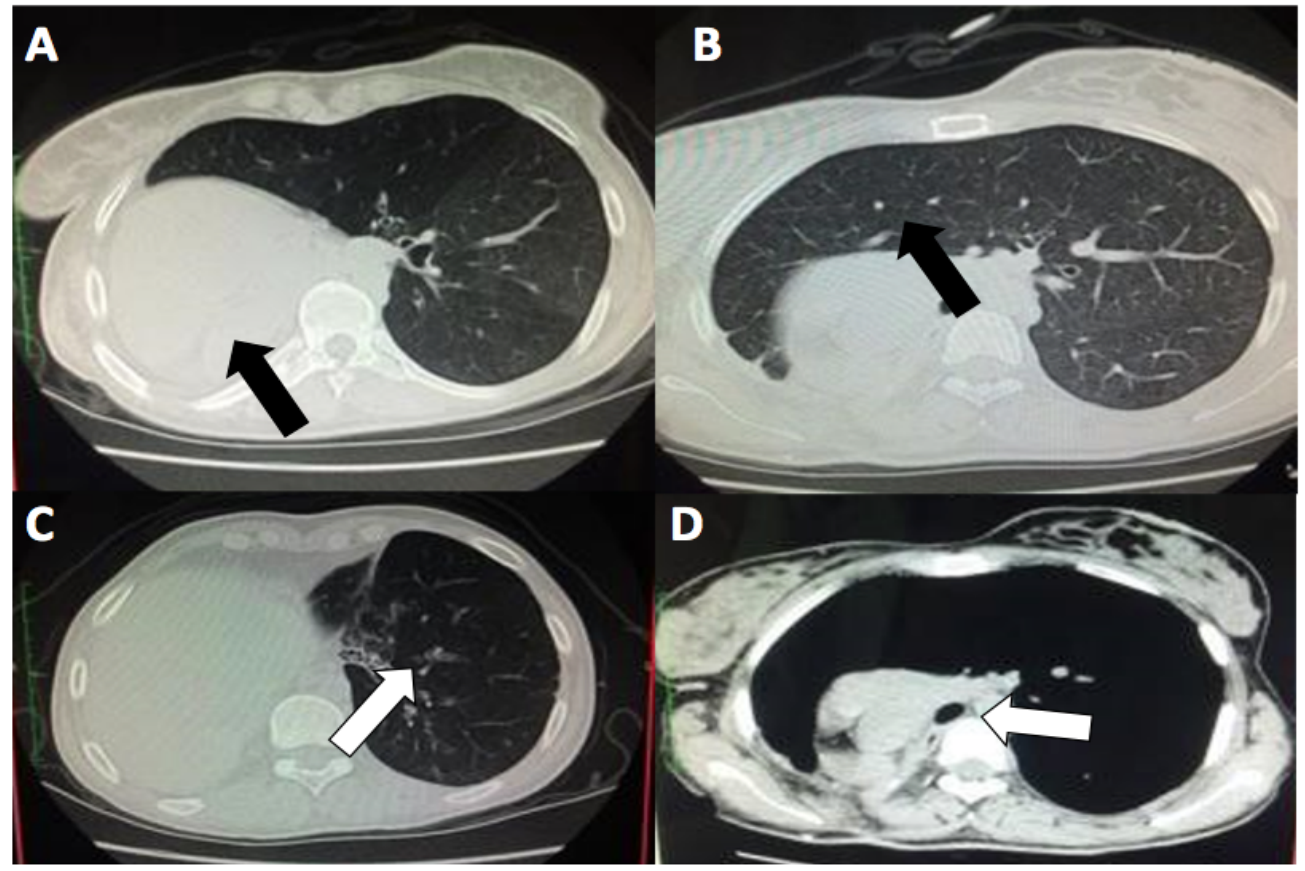

Figure 2: Chest tomography showing (evidenced by the narrows): A) Absence of the right lung; B) Hyperinflation of the contralateral lung; C) Bronchiectasis in the left upper lobe; and D) Deviation of the trachea and mediastinal structures to the right side. 
fact, it was found that patients diagnosed at an early stage generally did better than those diagnosed at a later stage [16].

There are many reasons for late diagnosis in CF. Mild or absent symptoms may delay a patient seeking medical attention, a physician may not suspect of CF in a patient with atypical symptoms, and some tests, such as the sweat test, can present normal or borderline results. Normally, pulmonary infections are the reason an adult is diagnosed with CF, and GIT symptoms rarely lead to diagnosis [16].

Therefore, a physician can suspect of CF in an adult, even though this pathology is taught as an infant disease. Certain pulmonary signs, however, such as recurrent pneumonia, progressive obstruction possibly identified as asthma or chronic obstructive pulmonary disease, chronic sinusitis, or nasal polyposis can lead to suspicious CF $[19,20]$. Among GIT symptoms in atypical CF, it can be included chronic constipation or diarrhea and chronic or recurrent pancreatitis [21].

Delay in the diagnosis can lead to substantial morbidity and several hospitalizations that might be avoided. There are excellent treatments for the various symptoms of $\mathrm{CF}$, including chest physiotherapy, antibiotic therapy, diet modification, and pancreatic enzyme replacement. Thus, a closer relationship with a clinician can help identify other complications and appropriate treatment can be offered, improving quality of life and life expectancy to those who are affected by CF.

\section{Acknowledgements}

I would like to acknowledge the staff of the Pulmonology Outpatient Clinic of the Presidente Prudente Regional Hospital, and Dr. Ricardo Beneti, Dr. Guilherme Zimmerer and Dr. Helbert de Luca for helping us with all the data.

\section{References}

1. Guggino WB, Banks-Schlegel SP (2004) Macromolecular interaction and ion transport in cystic fibrosis. Am J Respir Crit Care Med 170: 815-820.

2. Johnson LG, Boyles SE, Wilson J, Boucher RC (1995) Normalization of raised sodium absorption and raised calcium-mediated chloride secretion by adenovirus-mediated expression of cystic fibrosis transmembrane conductance regulator in primary human cystic fibrosis airway epithelial cells. J Clin Invest 95: $1377-1382$

3. Stutts MJ, Canessa CM, Olsen JC, Hamrick M, Cohn JA, et al. (1995) CFTR as a cAMP-dependent regulator of sodium channels. Science 269: 847-850.

4. Reis JF, Damaceno N (1998) Cystic Fibrosis. J Pediatr 74: S76-S79.
5. https://www.cff.org/about_cf/what_is_cf/

6. Griese M, Kappler M, Gaggar A, Hartl D (2008) Inhibition of airway proteases in cystic fibrosis lung disease. Eur Respir J 32: 783-795.

7. Davis PB (1993) Pathophysiology of the lung disease in cystic fibrosis. In Davis PB (ed.) Cystic Fibrosis. New York: Marcel Dekker, pp: 193-199.

8. Howen RH, van der Doef HP, Sermet I, Munck A, Hauser B, et al. (2010) Defining DIOS and constipation in cystic fibrosis with a multicenter study on the incidence, characteristics, and treatment of DIOS. J Pediatr Gastroentero Nutr 50: 38-42.

9. Khoshoo V, Udall JN (1994) Meconium ileus equivalent in children and adults Am J Gastroenterol 89: 153-157.

10. Tabori H, Arnold C, Jaudszuz A, Mentzel HJ, Renz DM, et al. (2017) Abdominal symptons in cystic fibrosis and their relation to genotype, history, clinical and laboratory findings. PLoS ONE 12: e0174463.

11. Rafeeq MM, Murad HAS (2017) Cystic fibrosis: current therapeutic targets and future approaches. J Transl Med 15: 84-92.

12. Castellani C, Southern KW, Brownlee K (2009) European best practice guideline for cystic fibrosis neonatal screening. J Cyst Fibros 8: 153-173.

13. Dijk FN, McKay K, Barzi F, Gaskin KJ, Fitzgerald DA (2011) Improved survival in cystic fibrosis patients diagnosed by newborn screening compared to a historical cohort from the same centre. Arch Dis Child 96: 1118-1123.

14. Schram CA (2012) Atypical cystic fibrosis: identification in the primary care setting. Can Fam Physician 58: 1341-1345.

15. Widerman E (2003) Knowledge, interests and educational needs of adults diagnosed with Cystic Fibrosis after age 18. J Cyst Fibros 2: 97-104.

16. Gan KH, Geus WP, Bakker W, Lamers CB, Heijerman HG (1995) Genetic and clinical features of patients with cystic fibrosis diagnosed after the age of 16 years. Thorax 50: 1301-1304.

17. McWilliams TJ, Wilsher ML, Kolbe J (2000) Cystic fibrosis diagnosed in adult patients. N Z Med J 113: 6-8.

18. Widerman E, Millner L, Sexauer W, Fiel S (2000) Health status and sociodemographic characteristics of adults receiving a cystic fibrosis diagnosis after age 18 years. Chest 118: 427-433.

19. Paranjape SM, Zeitlin PL (2008) Atypical cystic fibrosis and CFTR-related diseases. Clin Rev Allergy Immunol 35: 116-123.

20. Ziedalski TM, Kao PN, Hening NR, Jacobs SS, Ruoss SJ (2006) Prospective analysis of cystic fibrosis transmembrane regulator mutations in adults with bronchiectasis or pulmonary nontuberculous mycobacterial infection. Chest 130: 995-1002.

21. Gilljam M, Ellis L, Corey M, Zielenski J, Durie P, et al. (2004) Clinica manifestations of cystic fibrosis among patients with diagnosis in adulthood. Chest 126: 1215-1224. 